\section{La Semana Pasada Hemos Hecho Y}

\section{Hoy Hicimos: Os Pretéritos Perfecto}

\section{Simple e Perfecto Compuesto na}

Variedade Septentrional do Espanhol

\section{Peninsulare Normas, Variação e Ensino}

\author{
La Semana Pasada Hemos Hecho Y Hoy Hicimos: The Past Perfecto \\ Simple and Perfecto Compuesto in the Northern Variety of Peninsular \\ Spanish
}

André Silva Oliveira ${ }^{*}$

RESUMO: Neste artigo, aborda-se o uso dos pretéritos perfecto simple e perfecto compuesto na variedade septentrional do espanhol peninsular. Nesse intuito, toma-se como aporte teórico o que é predisposto na Nueva Gramática de la Real Academia Espańola da Real Academia Espanhola (2010) e em trabalhos relativos às formas pretéritas simples e composta e o uso dos marcadores temporais de anterioridade e de antepresente nesta variedade do espanhol peninsular, ancorando ambas as formas pretéritas. Para isso, foram selecionadas 20 entrevistas, equitativamente distribuídas entre as regióes de Alcalá de Henares, Madrid, Galicia e Valencia em um córpus linguístico oral, o Proyecto para el Estudio Sociolingüístico del Español de España y América (PRESEEA). Após a análise dos dados, verificou-se que, ainda que seja predominante o emprego de marcadores temporais de antepresente com o pretérito perfecto compuesto e marcadores de anterioridade com o pretérito perfecto simple, houve uma significativa porcentagem de uso de marcadores de antepresente ancorando a forma pretérita simples (13\%), em razão de um antigo vestígio deste tipo pretérito, na variedade septentrional espanhola, relativo a passados imediatos; e uma relativa porcentagem de marcadores de anterioridade ancorando a forma pretérita composta (6,3\%), em virtude de uma interpretação subjetiva do falante no que diz respeito ao evento passado, relacionando-o ao momento de fala.

PALAVRAS-CHAVE: Língua Espanhola; Preteridade; Córpus Oral.

ABSTRACT: In this article, the use of the past perfecto simple and perfecto compuesto in the northern variety of peninsular Spanish is approached. In order to do so, we take as a theoretical contribution what is predisposed in the Nueva Gramática de la Real Academia Española of the Royal Spanish Academy (2010) and in works related to the simple and compound past forms and the use of the anterior

\section{Linguagęm Foco \\ Revista do Programa de Pós-Graduação em Linguística Aplicada da UECE}

Mestre em Linguística. Doutorando em Linguística pelo Programa de Pós-Graduação em Linguística da Universidade Federal do Ceará (PPGL/UFC). Contato: andrethtzn@gmail.com.
Distribuído sobre

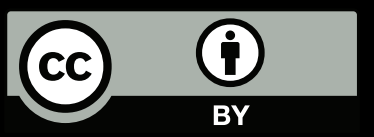


and previous time markers in this variety of peninsular Spanish, anchoring both past forms. For this, 20 interviews were selected, equally distributed among the regions of Alcalá de Henares, Madrid, Galicia and Valencia in an oral linguistic body, the Proyecto para el Estudio Sociolingüístico del Español de España y América (PRESEEA). After the analysis of the data, it was found that, although the use of the present markers with the perfecto compuesto and anteriority markers with the perfecto simple was predominant, there was a significant percentage of use of present markers anchoring the simple past tense (13\%), due to an ancient trace of this past tense type, in the Spanish northern variety, relating to immediate past; and a relative percentage of anteriority markers anchoring the present perfect $(6.3 \%)$, due to a subjective interpretation of the speaker with respect to the past event, relating it to the moment of speech.

KEYWORDS: Spanish Language; Preterity; Oral Corpus.

\section{INTRODUÇÃO}

Como é sabido, os pretéritos perfecto simple e perfecto compuesto do espanhol, na variedade septentrional peninsular, apresenta usos "bem delimitados", sendo empregados, respectivamente, para se referir a: (i) eventos passados e finalizados, cujo tempo de concretização já não se encontra mais em curso; e (ii) eventos passados e concluídos, cujo tempo de realização ainda se encontra em curso.

A partir desse conhecimento, pensou-se em descrever e analisar os usos de ambos os pretéritos em zonas septentrionais espanholas, a saber: Alcalá de Henares, Madrid, Santiago de Compostela e Valencia; no intuito de se averiguar a ancoragem dos marcadores temporais de antepresente (hoy, esta mańana, esta semana, ahora, etc.) e de anterioridade (anteayer, ayer, la semana pasada, el día anterior, etc.) sobre essas formas pretéritas. Por isso, foram selecionadas 20 entrevistas, equitativamente distribuídas entre as regiôes selecionadas, em um córpus oral de língua espanhola, o Proyecto para el Estudio Sociolingüístico del Español de España y América (PRESEEA).

Desse modo, no intuito de se fazer uma abordagem dos pretéritos perfecto simple e perfecto compuesto na variedade septentrional peninsular, recorreu-se ao que é predisposto pela Nueva Gramática de la Real Academia Española em relação às formas pretéritas simples e composta, na primeira seção. Posteriormente, na segunda seção, buscou-se, na literatura existente, referencial teórico sobre os contextos de uso do perfecto simple e perfecto compuesto na zona septentrional da Espanha. Na sequência, na terceira seção, abordase acerca da metodologia empregada nesta pesquisa, bem como a apreciação das categorias de análise e a delimitação do córpus. Em seguida, discorre-se sobre os resultados e discussões de uso das formas pretéritas simples e composta nas entrevistas selecionadas. Por fim, disserta-se sobre as considerações finais com base nos resultados encontrados.

\section{OS PRETÉRITOS PERFECTO SIMPLE E PERFECTO COMPUESTO NA PERSPECTIVA DA REAL ACADEMIA ESPANHOLA - RAE (2010)}

A Nueva Gramática de la Real Academia Española proposta pela Real Academia Espanhola - RAE (2010), em colaboração com as demais academias de língua espanhola do mundo hispânico, estabelece que o pretérito perfecto simple indica anterioridade em relação ao momento de fala, enquanto o pretérito 
perfecto compuesto indica anterioridade com relação a um momento situado no presente. Isso pode ocasionar algumas series de conflitos, ainda que a forma composta expresse alguma persistência atual com os fatos passados, enquanto a forma simples denota fatos anteriores ao momento de fala.

Em relação ao pretérito perfecto compuesto, averígua-se, a partir do que é predisposto pela RAE (2010), que este tempo passado expressa sua propriedade de antepresente em sua própria estrutura sintática, haja vista que se forma a partir do presente do indicativo da forma auxiliar do verbo haber com o particípio passado do verbo principal: he [presente del verbo haber] + participio pasado. Devido a estas propriedades sintáticas (verbo auxiliar no presente e verbo principal no particípio passado), alguns valores semânticos fundamentais, de acordo com RAE (2010), são-lhe atribuídos, tais como a interpretação:

(i) de antepresente, em que se usa para fazer referência a situaçóes anteriores ao momento de fala, mas ainda avaliadas desde a perspectiva do momento de fala, ou seja, ainda com ligaçáo ao momento presente, como nos exemplos: Ha sufrido mucho en la vida e Ha llegado hace un rato (RAE, 2010, p. 2734);

(ii) perfectiva ou de aoristo, em que se usa para referir-se a açôes finalizadas e situadas em um marco temporal de maior amplitude, como no exemplo: Ha llegado hace dos meses (RAE, 2010, p. 2734);

(iii) de pressuposição existencial, que indica a persistência de existência do sujeito referenciado na oração, como exemplo: Arturo ha estado tres veces en Buenos Aires durante este año (RAE, 2010, p. 2736); implicando a existência de Arturo;

(iv) prospectiva ou de planificação, que remete a açôes futuras, como no exemplo: Mañana a estas horas, seguro que ya hemos terminado el informe (RAE, 2010, p. 2737);

(v) habitual ou interativa, que são relativas à continuidade das ações começadas em um tempo anterior ao momento de fala, mas que ainda perduram, como nos exemplos: Pero cada vez que ha reasomado, le hemos utilizado e Hay un teléfono en su despacho que siempre que ha sonado le ha alejado de la realidad carcelaria (RAE, 2010, p. 2737);

(vi) experiencial, que é relativa a fatos que aconteceram mais de uma vez em um período que pode ser fixado de forma arbitrária, como no exemplo: Arturo ha estado tres veces en Santiago en el último año (RAE, 2010, p. 2739);

(vii) de aspecto contínuo, que é empregado em contextos nos quais a situação é descrita por meio de predicados atélicos, ou seja, a situação não cessa até o momento de fala, como no exemplo: Durante tres dias no hemos podido cruzar palabra (RAE, 2010, p. 2740);

(viii) de fatos recentes ou de passado imediato, em que a distância temporal permite caracterizar esses fatos em um momento recente, tendo em vista que o período em que elas sucederam ainda não terminou, resguardando relação com o momento de fala, sendo empregado para isso algumas expressôes que indicam a proximidade como o presente, como el día de hoy, la semana, el mes o el año actuales, etc., como nos exemplos: ¿Te has acordado de tu madre en todo el dia?l ¿Y qué has hecho después hasta las diez de la noche?/ Hoy Rosi me ha preguntado una cosa curiosal Yo he venido ahora por conocerla a usted (RAE, 2010, p. 2746).

No tocante ao pretérito perfecto simple, constata-se, com base na RAE (2010), que este tempo passado simples guarda alguns traços dêiticos ou referenciais prototípicos de temporalidade passada (pretérito), aspecto (perfectividade) e morfológico (simples). Com o pretérito perfecto simple faz-se referência a fatos 
completamente finalizados, mas sem que estes sejam pontuais, ou seja, que guardem relaçáo com o momento de fala. Refere-se, geralmente, a estados-de-coisas que ocupam certa extensão temporal, quase sempre limitada, como nos exemplos: Escribió versos durante toda su vida e Vivieron varios años en el extranjero (RAE, 2010, p. 2756).

Ainda conforme a RAE (2010, p. 2757), o pretérito perfecto simple é compatível tanto com predicados télicos (consequências e realizaçóes), como nos exemplos: llegaron, murió, leí la novela, visitaste al médico, etc.; como com os predicados atélicos, como nos exemplos: empujé el carro, duró dos horas, trabajaron incansablemente, fue aviador, escribieron cartas, etc.; o que é deduzido, portanto, da diferença entre a delimitaçáo externa e interna dos predicados. Outra característica importante deste tempo passado refere-se aos limites inicial e final dos eventos descritos, isto é, tratam-se de ações começadas e totalmente finalizadas em um momento anterior ao de fala, como no exemplo: Arturo leyó Guerra y Paz el mes pasado (RAE, 2010, p. 2756); expressa que a leitura do romance já foi finalizada.

É possível observar em língua espanhola, de acordo com a RAE (2010), que em muitas ocasiões o uso do pretérito perfecto simple apresenta natureza icônica, já que sugere a ordem em que os eventos aconteceram de forma concatenada, como nos exemplos: Sintió un pinchazo y se puso la mano en el pecho e Llegué, vi y vencí (RAE, 2010, p. 2758). Outra interpretação possível por meio do uso deste tempo verbal é de interpretação incoativa (também chamada de ingressiva ou inceptiva) dos predicados de realização de algum evento, geralmente ancorados por meio de adjuntos temporais, como por exemplo: El tren llegó a las tres (RAE, 2010, p. 2758); indicando o momento em que o trem chegou, ao invés de dar a entender que essa ação se realiza em um dado momento. A interpretação incoativa também é característica de certos predicados que ocupam intervalos breves, como no exemplo: Lavé los platos después de comer (RAE, 2010, p. 2758).

Em resumo, com base na RAE (2010), infere-se que os pretéritos perfecto simple e perfecto compuesto são relativos a ações passadas e finalizadas (perfectividade), diferenciando-se, especificamente, quanto ao marco temporal do evento passado. Enquanto o pretérito perfecto simple localiza o evento para um tempo já finalizado e sem ligação com o momento de fala, o pretérito perfecto compuesto, por sua vez, localiza o evento em um marco de tempo ainda em transcurso, ou seja, ainda relacionado ao momento de fala.

Sabendo-se da caracterização dos pretéritos perfecto simple e perfecto compuesto sob a ótica da RAE (2010), apresentar-se-á, na seção seguinte, alguns contrastes de uso entre estes tempos pretéritos na variedade septentrional do espanhol peninsular.

\section{O CONTRASTE ENTRE OS PRETÉRITOS PERFECTO SIMPLE E PERFECTO COMPUESTO NA VARIEDADE SEPTENTRIONAL DO ESPANHOL PENINSULAR}

De acordo com Kempas (2006), na variedade septentrional do espanhol peninsular, que abrange as regióes centro-norte da Espanha, a saber: Galicia, Asturias, Cantabria, Aragón, Castilla y León, Navarra, La Rioja, El País Vasco, Comunidad de Madrid, Valencia e Cataluña; tendem a diferenciar, de maneira mais específica, o pretérito perfecto simple do pretérito perfecto compuesto. Nesse sentido, os falantes nativos 
destas zonas empregam o perfecto simple em contextos de anterioridade ao momento de fala, cujo o evento e o marco temporal encontram-se definitivamente finalizados, enquanto o perfecto compuesto é utilizado para referir-se a açóes passadas e finalizadas, mas dentro de um marco temporal ainda em curso.

Ainda conforme o autor, ambos os pretéritos são auxiliados por marcadores temporais que auxiliam nessa diferença temporal, isto é, geralmente os falantes recorrem a expressôes de tempo que sinalizam finalização do tempo referente ao evento passado descrito (ayer, anteayer, hace dos días, la semana pasada, el año pasado, hace tres años, etc.), como nos exemplos: Ayer compré una camiseta roja e Hace una semana visitó a su tía (KEMPAS, 2006, p. 48); e expressóes de tempo que designem que o tempo, em que o evento ocorreu, ainda está em curso (hoy, esta mañana, esta semana, este mês, en este día, etc.), como no exemplo: Hoy he comido a la una (KEMPAS, 2006, p. 49).

Conforme Oliveira (2007), na variedade septentrional peninsular, a principal característica que difere o perfecto simple do perfecto compuesto é a relação com o momento da enunciaçáo, em que o primeiro significa anterioridade do atributo (evento passado) em relação ao momento de fala, enquanto o segundo significa que o atributo (evento passado) tem relaçáo com alguma coisa que ainda existe, persiste no momento de fala. Em outras palavras, enquanto o perfecto simple é empregado para se referir a fatos passados, o perfecto compuesto se aplica a fatos que ainda guardam relação com o presente. Para Santos (2009), ainda que o perfecto simple e o perfecto compuesto tenham em comum o fato de indicarem uma relação de anterioridade com relação ao momento de fala, ambos indicam açôes perfeitas (perfectividade), concluídas em um momento anterior ao momento de fala. No entanto, a diferença predominante, na variedade septentrional peninsular, reside no fato de que a forma simples aponta para uma mera anterioridade em relação ao momento de fala, do qual se separa, constituindo, dessa forma, um âmbito próprio no passado; enquanto a forma composta indica a anterioridade dentro do âmbito do presente, pertencente, desse modo, à atualidade do falante.

Ainda segundo a autora, na variedade septentrional peninsular, a principal oposição aspectual entre o perfecto simple e o perfecto compuesto está na percepção do falante da conexáo entre o evento passado descrito e o momento de fala. Por isso, se o falante pretende expressar que a situaçáo passada pertence a um período de tempo divergente do momento em que ele está falando, recorre, então, à forma simples. Contudo, se o falante deseja expressar que a situação passada ainda pertence ao período de tempo que, no momento da comunicação, é ainda atual, ele faz uso da forma composta. Para a autora, ainda que o falante possa recorrer a marcadores temporais próprios que indiquem marco temporal finalizado ou em curso, isso não significa que ele tenha que explicitar por meio de unidades linguísticas, podendo empregar apenas as formas simples e composta para expressar por si só a finalização do tempo ou indicar que o tempo ainda está em curso. A autora ainda ressalva que:

Também se deve levar em conta que a aproximação da situação de passado com o momento da fala não é o critério que determina a escolha entre o simples e o composto, uma vez que, por um lado, uma situação passada muito recente pode ser considerada que ocorreu em um período de tempo separado do momento da fala, e por outro lado, o falante pode julgar que o período de tempo em que tem lugar o ato de fala se estende indefinidamente em direçáo ao passado e incluir situaçóes que começaram há muito tempo (SANTOS, 2009, p. 35). 
Em relação à forma estrutural entre o perfecto simple e o perfecto compuesto, pode afirmar, de acordo com Lochte (2014), que o fato da forma simples possuir apenas uma única estrutura temporal (pretérita) facilita que esta seja interpretada, aspectualmente, como perfectiva ou de aoristo; enquanto a forma composta, por apresentar uma forma temporal dual (presente e particípio passado), seja interpretada tanto como antepresente (em virtude do verbo auxiliar ser conjugado no presente do indicativo) quanto perfectiva ou de aoristo (em razão do verbo principal ser conjugado no particípio passado). Nesse sentido, conforme a autora, é natural que, na variedade septentrional peninsular, os falantes recorram a certos matizes (marcadores temporais próprios que indiquem a finalização ou que o marco temporal ainda segue em curso) no uso de ambos os pretéritos com interpretação aorística. Ainda de acordo com a autora, ainda que ambos os pretéritos tenham em comum a perfectividade dos eventos e característica de serem aorísticos, o fato de a forma composta ser um tempo relativo e a forma simples ser um tempo absoluto, será determinante para a caracterização desses matizes de diferenciação entre ambos os pretéritos, haja vista que os centros dêiticos para um e outro tempo verbal não coincidem.

Segundo Lochte (2014), o perfecto compuesto é um tempo relativo, ou seja, o seu centro dêitico se encontra no momento da enunciação. No entanto, o perfecto simple, por ser um tempo absoluto, atua por si só como centro dêitico, sem necessidade de outra referência. Dessa forma, os centros dêiticos determinarão os complementos temporais que concordem ou não com estes tempos verbais pretéritos. Nesse sentido, enquanto a forma composta combina com complementos de simultaneidade e rechaça as formas de anterioridade, a forma simples atua de maneira contrária, isto é, rechaça os marcadores temporais de simultaneidade, preferindo por aqueles que indiquem anterioridade, como nos exemplos: Pedro ha ido a trabajar hoy / *Pedro ha ido a trabajar ayer / Pedro fue a trabajar ayer / *Pedro fue a trabajar hoy (LOCHTE, 2014, p. 28); em que o emprego do perfecto compuesto localiza o evento passado em um lugar próximo ao momento de fala, enquanto o uso do perfecto simple situa o evento passado em um momento que está fora do limite hodiernal.

Resumidamente, na variedade septentrional peninsular, as diferenças de uso entre o perfecto simple e o perfecto compuesto são basicamente temporais, no sentido de que o uso de uma forma ou de outra depende fundamentalmente da distância temporal do evento em relação ao momento da enunciação.

Sabendo-se das formas de uso dos pretéritos perfecto simple e perfecto compuesto na variedade septentrional peninsular, passar-se-á, na seção seguinte, para a metodologia que rege esta pesquisa, bem como a delimitação do córpus e a apreciação das categorias de análise.

\section{METODOLOGIA}

Tendo por objetivo descrever e analisar qualitativa e quantitativamente os usos dos pretéritos perfecto simple e perfecto compuesto na variedade septentrional peninsular, recorreu-se ao córpus Proyecto para el Estudio Sociolingüistico del Español de España y América (PRESEEA), disponível em: <http:// preseea.linguas.net>, com acesso em: $31 \mathrm{dez}$. 2019; em que foram selecionadas 20 entrevistas, das seguintes cidades situadas na região septentrional da Espanha: Alcalá de Henares ( 5 entrevistas), Madrid (5 entrevistas), Santiago de Compostela (5 entrevistas) e Valencia (5 entrevistas). O Quadro 01 aborda, de 
maneira mais detalhada, a composição do córpus:

Quadro 01: As entrevistas que compuseram o córpus da pesquisa

\begin{tabular}{|c|c|c|}
\hline $\begin{array}{l}\text { Regiáo septentrional da } \\
\text { Espanha } \\
\text { Alcalá de Henares }\end{array}$ & $\begin{array}{c}\text { Código da entrevista no } \\
\text { PRESEEA } \\
\text { ALCA H11 } 037\end{array}$ & $\begin{array}{c}\text { Número da entrevista no } \\
\text { SPSS } \\
\text { Entrevista } 01\end{array}$ \\
\hline Alcalá de Henares & ALCA_H12_019 & Entrevista 02 \\
\hline Alcalá de Henares & ALCA_H13_001 & Entrevista 03 \\
\hline Alcalá de Henares & ALCA_H21_043 & Entrevista 04 \\
\hline Alcalá de Henares & ALCA_H22_025 & Entrevista 05 \\
\hline Madrid & MADR_H13_013 & Entrevista 01 \\
\hline Madrid & MADR_H23_033 & Entrevista 02 \\
\hline Madrid & MADR_H33_049 & Entrevista 03 \\
\hline Madrid & MADR_M13_018 & Entrevista 04 \\
\hline Madrid & MADR_M23_034 & Entrevista 05 \\
\hline Santiago de Compostela & SCOM_H12_027 & Entrevista 01 \\
\hline Santiago de Compostela & SCOM_H13_012 & Entrevista 02 \\
\hline Santiago de Compostela & SCOM_H21_039 & Entrevista 03 \\
\hline Santiago de Compostela & SCOM_H22_024 & Entrevista 04 \\
\hline Santiago de Compostela & SCOM_H23_017 & Entrevista 05 \\
\hline Valencia & VALE_H11_065 & Entrevista 01 \\
\hline Valencia & VALE_H12_042 & Entrevista 02 \\
\hline Valencia & VALE_H13_020 & Entrevista 03 \\
\hline Valencia & VALE_H21_057 & Entrevista 04 \\
\hline Valencia & VALE_M33_010 & Entrevista 05 \\
\hline
\end{tabular}

Fonte: Elaborado pelo autor com base nos dados do PRESEEA e nos dados do SPSS

Reitera-se que as entrevistas selecionadas tiveram como único critério a procedência dos entrevistados, no caso, da região septentrional da Espanha, sendo desconsideradas categorias como sexo, idade, grau de escolaridade, etc., haja vista que esta pesquisa não tem por pretensão fazer uma análise variacionista de uso de ambos os pretéritos na variedade septentrional da Espanha.

Em relação às categorias de análise, pautaram-se duas: (i) o tipo de pretérito empregado pelo falante, no caso, pretérito perfecto simple ou pretérito perfecto compuesto; e (ii) o tipo de marcador temporal que ancora o uso do tempo pretérito, em questão, marcadores temporais de antepresente (hoy, este día, esta semana, este mes, etc. ) e marcadores temporais de anterioridade (aye, anteayer, la semana pasada, el mes pasado, etc.). Dessa forma, a seleção das ocorrências foi pautada tanto no tipo de pretérito empregado quanto no uso do marcador temporal, ou seja, foram selecionados apenas os casos em que ocorriam, no mesmo contexto de fala, o pretérito perfecto simple e/ou o pretérito perfecto compuesto ancorados por meio de algum marcador temporal (advérbios de tempo, locuçôes adverbiais de tempo, construçôes temporais, etc.), que remetiam a um marco temporal já finalizado (anterioridade) ou ainda em curso (antepresente).

Para a análise dos dados utilizou-se: (i) para a parte qualitativa, o que é predisposto na Nueva 
Gramática de la Real Academia Española e em trabalhos referentes ao uso de ambos os pretéritos na variedade septentrional peninsular; e (ii) para a parte quantitativa, o Statistical Package for the Social Sciences (SPSS) versão 22 para o Windows para a rodagem dos dados e cruzamento das variáveis.

Tendo feita a categorização do córpus e a apreciação das categorias de análise, passar-se-á, na seção seguinte, para a descrição e análise dos casos relativos ao uso dos pretéritos perfecto simple e perfecto compuesto na variedade septentrional peninsular.

\section{RESULTADOS E DISCUSSÓES}

O propósito deste trabalho consiste em descrever e analisar o uso dos pretéritos perfecto simple e perfecto compuesto ancorados por meio de marcadores temporais de antepresente (hoy, esta semana, este mes, este año, etc.) e de anterioridade (ayer, la semana pasada, el mes pasado, el día anterior, etc.) na variedade septentrional do espanhol peninsular, considerada uma zona conservadora no que diz respeito à diferença de uso entre ambos os pretéritos (KEMPAS, 2006). Primeiramente, far-se-á uma abordagem da frequência de uso dos pretéritos perfecto simple e perfecto compuesto. Na sequência, abordar-se-á acerca dos tipos de marcadores temporais empregados e que ancoraram os pretéritos perfecto simple e perfecto compuesto. Por fim, analisar-se-á o cruzamento entre os tipos de marcadores temporais empregados e os tipos de pretéritos encontrados no córpus.

Em relação à frequência de uso dos pretéritos perfecto simple e perfecto compuesto na variedade septentrional do espanhol peninsular, a Tabela 01 traz essa frequência e as porcentagens relativas a elas:

\section{Tabela 01: Frequência dos pretéritos perfecto simple e perfecto compuesto na variedade septentrional do espanhol peninsular}

\begin{tabular}{ccc}
\hline Tipo de pretérito & Frequência & Porcentagem \\
\hline Perfecto compuesto & 174 & $55,1 \%$ \\
\hline Perfecto simple & 142 & $44,9 \%$ \\
\hline Total & 316 & $100 \%$ \\
\hline
\end{tabular}

Fonte: Elaborado pelo autor com base nos dados do SPSS

Com base na Tabela 01, verifica-se que o pretérito perfecto compuesto é o mais recorrente $(55,1 \%)$, seguido pelo perfecto simple (44,9\%). Isso se justifica, se se considera que, em relação ao gênero entrevista, há uma dinâmica no turno de fala entre o entrevistador e o entrevistado, em que aquele busca saber informaçôes referentes a eventos tanto relativos a um tempo ainda em curso, empregando para isso marcadores temporais de antepresente, quanto a eventos referentes a um tempo já finalizado e sem relação com o momento de fala. Outro ponto que pode ter alguma relevância com o fato de o perfecto compuesto ser o mais recorrente na fala dos entrevistados, na variedade do espanhol peninsular, deve-se a quantidade de matizes de uso deste tempo pretérito em comparação ao perfecto simple, haja vista que a forma composta

\begin{tabular}{c|c|c|c}
\hline Revista Linguagem em Foco & Fortaleza, CE & v. 12 n. 1 & ISSN 2674-8266 \\
\hline
\end{tabular}


é empregada para manifestar diferentes tipos de interpretação, tais como de: antepresente, perfectiva ou aoristo, pressuposição existencial, prospectiva ou planificação, habitual ou interativa, experiencial, aspecto contínuo e fatos recentes ou passado imediato; o que pode ser visto de (1) a (4):

(1) boy me ba tocado / irme con el coche a un pueblo a repartir alguna cosilla y tal / pues<alargamiento/> (ALCALÁ DE HENARES - ENTREVISTA 01)

(2) siempre lo he llevado fatal para dormir y<alargamiento/> ijo! / cuando no duermo es que estoy que me arrastro (MADRID - ENTEVISTA 01)

(3) hasta ahora // que este año // me han operao del hombro / porque tenía luxa <palabra_cortadal> $<$ vacilación/> una <término $>$ luxación </término $><$ ruido = "carraspeo"/> <silencio/> bueno varias / (VALENCIA - ENTREVISTA 02)

(4) hombre<alargamiento/> yo creo que ahora mismo en<alargamiento/> algunos sitios han intentado hacerlo<alargamiento (ALCALÁ DE HENARES - ENTREVISTA 01)

Em (1), verifica-se um caso de perfecto compuesto com interpretação de fato recente ou passado imediato, haja vista que se refere a um evento recente, em que o período em que ele sucedeu ainda segue em curso e, por isso, resguarda relaçáo com o momento de fala (no ato da entrevista), sendo ancorado pelo advérbio de tempo hoy. Por sua vez, em (2), constata-se um caso de perfecto compuesto com interpretação habitual ou interativa, pois é relativa à continuidade de uma ação ainda começada no passado e em um tempo anterior ao momento de fala, mas que ainda perdura, sendo ancorada por meio do advérbio de tempo siempre. Por seu turno, em (3), atesta-se um caso de interpretação perfectiva ou de aoristo, considerando que o emprego do perfecto compuesto refere-se a uma ação finalizada, mas situada em um marco temporal de maior amplitude e ainda em curso, o que é evidenciado pelo uso da construção temporal este año. Por fim, em (4), averígua-se um caso de interpretação de antepresente, em que o perfecto compuesto é utilizado para fazer menção a um evento anterior ao momento de fala, mas ainda avaliado desde a perspectiva do momento de fala, o que é atenuado pelo emprego do advérbio de tempo ahora.

Ainda em relação ao perfecto compuesto, foi registrado o uso de outros marcadores temporais, no caso, advérbios de negação (nunca e tampoco), que ancoraram o uso da forma composta, o que pode ser averiguado em (5) e (6):

(5) si y<alargamiento/> <vacilación/> / y nunca habia trabajado en una asesoría me habia dedicado todo <vacilación/ $>$ a todo menos a<alargamiento/>... a lo<alargamiento/> <vacilación/ $>$ a lo mio ¿sabes? porque la verdad es que no me ha gustado mucho nunca me he sentido muy atraido por ello / lo he hecho porque si pero / no me siento muy motivado con ello ¿sabes? (ALCALÁ DE HENARES - ENTREVISTA 03)

(6) no sé por qué ha sido pero tampoco be viajao mucho más que <vacilación/> / a Andorra de vez en cuando a esquia<alargamiento/>r / a barcelo <palabra_cortadal> la verdad es que a Barcelona he viajado mucho (VALENCIA - ENTREVISTA 03) 
Em (5), o falante manifesta por meio do advérbio de negação e o uso do pretérito perfecto compuesto a negação de ter sentido vontade de trabalhar com qualquer tipo de assessoria; enquanto, em (6), por meio do advérbio de negação e o uso da forma composta, o falante nega que tenha realizado muitas viagens ao longo de sua vida. De acordo com Lochte (2014), o emprego dos advérbios de negação nunca e tampoco ancorando o perfecto compuesto aportam uma leitura de perfeito experiencial, em que tais advérbios estabelecem a coincidência entre o tempo referente a duração total da vida do falante até o momento presente. Ainda segundo o autor, outros marcadores temporais podem também ancorar essa leitura de perfeito experiencial, tais como: todavía, aún, últimamente, alguna vez, etc., como é possível verificar de (7) a (9):

(7) porque todavía no me he acostado </cita> y como él estaban pues casi todos los jóvenes de<alargamiento/> dieciocho veintidós veinticuatro años (ALCALÁ DE HENARES ENTREVISTA 01)

(8) ¿has estado alguna vez asi en alguna situación comprometida? // (MADRID - ENTREVISTA 02)

(9) eso si lo be notado últimamente // pero en cuanto a<alargamiento/> las mejoras del barrio y eso si // aunque esta zona del barrio de Salamanca está un poco más descuidada que otras // (MADRID - ENTREVISTA 03)

De (7) a (9), nota-se que o perfecto compuesto está ancorado, respectivamente, pelos marcadores todavía, alguna vez e últimamente; para se referir a experiencias vividas ou ainda não vividas pelo o entrevistado(a).

No que diz respeito ao pretérito perfecto simple, constata-se que ele foi empregado para referirse a eventos finalizados e que estiveram circunscritos em um tempo também concluído e anterior ao momento de fala, o que pode ser visto de (10) a (12):

(10) jayer! / ayer ayer ayer <risas = "todos"> ;ayer! // el dia de la boda fue el veinticuatro de junio / y hacía un calo<alargamiento/>r / el día anterior / cayó una tormenta de estas de escándalo I y tuvimos que ir a Guadalajara / a buscar el traje de novia / (ALCALÁ DE HENARES ENTREVISTA 01)

(11) ya el año pasado cogieron y nos cortaron // comisión fija <silencio/> dices tú <cita> ijoder! / eso ¿a mi qué más me da <risas = "I"/> ganarle más a este coche o ganarle menos? (SANTIAGO DE COMPOSTELA - ENTREVISTA 01)

(12) la ansiedad también / yo fumé hace años // pero bace muchisimo que dejé de fumar / (SANTIAGO DE COMPOSTELA - ENTREVISTA 02)

De (10) a (12), o perfecto simple é empregado pelos falantes (as pessoas entrevistadas) para se referir a uma série de eventos que tiveram lugar em um momento anterior ao momento da entrevista, em que

\begin{tabular}{c|c|c|c}
\hline Revista Linguagem em Foco & Fortaleza, CE & v. 12 n. 1 & ISSN 2674-8266 \\
\hline
\end{tabular}


os verbos conjugados (fue, tuvimos, cayó, cogieron, cortaron, fumé e dejê) estáo ancorados por marcadores temporais que delimitam a não relação desses eventos com o momento da entrevista (ayer, el día anterior, el año pasado, hace años e hace muchísimo).

Em relação à frequência de uso dos marcadores temporais de antepresente e de anterioridade, a Tabela 02 traz essas frequências e a porcentagem delas no córpus:

\section{Tabela 02: Frequência dos marcadores temporais de antepresente e de anterioridade na variedade septentrional do espanhol peninsular}

\begin{tabular}{ccc}
\hline $\begin{array}{c}\text { Tipo de marcador } \\
\text { temporal }\end{array}$ & Frequência & Porcentagem \\
\hline Antepresente & 195 & $61,7 \%$ \\
\hline Anterioridade & 121 & $38,3 \%$ \\
\hline Total & 316 & $100 \%$ \\
\hline
\end{tabular}

Fonte: Elaborado pelo autor com base nos dados do SPSS

Como era de se esperar, já que houve um maior frequência de uso da forma composta em detrimento da forma simples no tocante ao uso dos pretéritos, que houvesse mais marcadores de antepresente $(61,7 \%)$ que de anterioridade (38,3\%). Isso pode ser explicado, como citado anteriormente, em razão de o perfecto compuesto apresentar mais matizes de uso do que o perfecto simple, podendo o falante (pessoa entrevistada) fazer uso de marcadores que restrinjam os eventos passados em um marco temporal ainda em curso, como se pode averiguar de (13) a (15):

(13) cumpliría con algunas de las<alargamiento/> <vacilación/> cosas<alargamiento/> que no be podido ha <palabra_cortadal> hasta el momento / por ejemplo / $\mathrm{mmm}$ tengo una deuda conmigo misma / que es aprender por lo menos algo de inglés / (VALENCIA - ENTREVISTA 05)

(14) y este año es que ha llovido muchi<alargamiento/>sino (MADRID - ENTREVISTA 05)

(15) ahora mismo también gente que be conocido con posterioridad y que no forma parte de ningún grupo / hh que también has mmm tenido una experiencia en común y que te ha <vacilación/> eeh te es es una gente más que tienes ahi ¿no? (MADRID - ENTREVISTA 02)

De (13) a (15), pode-se constatar que os marcadores temporais, respectivamente, hasta el momento, este año e ahora designam tempo ainda em curso ou a relaçáo do evento finalizado no passado com o momento de fala. Em outras palavras, a hodiernidade do evento passado (preteridade) por meio do uso da forma composta.

No entanto, o que chama a atenção, a partir dos dados encontrados após a rodagem das ocorrências, é a nítida porcentagem de uso de marcadores temporais de anterioridade ancorando o uso do perfecto 
compuesto (6,3\%); e os de antepresente ancorando o perfecto simple (13\%) na variedade septentrional do espanhol peninsular, como pode ser visto na Tabela 03:

Tabela 03: A inter-relaçáo entre os tipos de pretéritos e os usos dos marcadores temporais na variedade septentrional do espanhol peninsular

\begin{tabular}{cccc}
\hline \multirow{2}{*}{ Tipo de pretérito } & \multicolumn{2}{c}{ Tipo de marcador } & Total \\
\cline { 2 - 3 } & Antepresente & Anterioridade & \\
\hline Perfecto compuesto & $154(48,7 \%)$ & $20(6,3 \%)$ & $174(55,1 \%)$ \\
\hline Perfecto simple & $41(13 \%)$ & $101(32 \%)$ & $142(44,9 \%)$ \\
\hline Total & $195(61,7 \%)$ & $121(38,3 \%)$ & $316(100 \%)$
\end{tabular}

Fonte: Elaborado pelo autor com base nos dados do SPSS

Com base nos dados da Tabela 03, é possível ver que, na variedade septentrional do espanhol peninsular, foi possível detectar a alternância dos marcadores temporais de antepresente e de anterioridade em relação ao uso das formas pretéritas simples e composta, como se pode ver nas ocorrências de (16) a (21):

O pretérito perfecto compuesto com marcador temporal de anterioridade:

(16) <simultáneo > no<alargamiento/> porque </simultáneo > es que con el<alargamiento/> es que mi mujer cambia de trabajo ahora... yo<alargamiento/> he cambiado la semana pasada entonces estamos ahi un poco<alargamiento/> (MADRID - ENTREVISTA 02)

(17) verdaderamente se puede decir que buena con tres ascensores / de subida y bajada tal / y ahi hemos estado / pues hasta<alargamientol> el año pasado (MADRID - ENTREVISTA 03)

(18) y tengo que estudiar / y en agosto yo lo he pasado fatal aqui porque tenemos el aire acondicionado pero si no<alargamiento/> imposible (MADRID - ENTREVISTA 04).

O pretérito perfecto simple com marcador temporal de antepresente:

(19) total que eeh lo he tenido alquilado / constantemente / y ahora últimamente se quedó <alargamiento/> vacio / que no es problema porque yo el piso no ha estado nunca parado (MADRID - ENTREVISTA 03)

(20) <simultáneo > no no </simultáneo > no no / tengo ganas de hacer un viajecillo por alli eh hoy / boy por la mañana marchó <alargamiento/> mi vecina para Perú // <risas = "I"/> se pira para allá porque // di <palabra_cortadal> digamos que los vecinos de alli del edifico desde los / doce $<$ alargamiento/> años eeh // yo llevo desde los doce / esta <alargamiento/> te <palabra_cortadal> tenía once cuando fue para alli (SANTIAGO DE COMPOSTELA - ENTREVISTA 01).

(21) <simultáneo> de pasar / bueno abora bicieron / no </simultáneo > sabes que hicieron el Sarela y un paseo todo por ahi abajo <observación_complementaria = "fático $=E " />$ ¿no? I (SANTIAGO DE COMPOSTELA - ENTREVISTA 03). 
No que diz respeito ao uso da forma pretérita composta com marcadores temporais típicos de anterioridade, pode-se inferir que as formas dêiticas usadas pelos falantes, tais como ahora, ahi e aquí, possam interferir no entendimento do falante de que a temporalidade dos eventos ocorridos (em um momento anterior ao da entrevista) ainda estejam em curso, influenciando, portanto, na semântica dos marcadores temporais de anterioridade utilizados, no caso, la semana pasada, el año pasado e en agosto (como algo ainda recente). Desse modo, tais eventos podem ser entendidos, por parte do falante, ainda como algo recente e relacionados a situaçôes experienciadas por ele no momento da entrevista. De acordo com Lochte (2014), o uso de marcadores temporais de anterioridade ancorando o perfecto compuesto tratase de uma percepção subjetiva do falante em relação ao evento experienciado e finalizado no passado, mas ainda entendido por ele como relevante e vigente no momento da enunciaçáo. Dessa forma, poderse-ia apontar um novo matiz de uso para a forma composta, o de percepção subjetiva do evento como algo recente e relacionado ao momento presente.

Por sua vez, em relação ao uso da forma pretérita simples com marcadores temporais típicos de antepresente, averígua-se, em conformidade com Lochte (2014), que isso possa ter relação com um antigo vestígio de uso do perfecto simple para se referir a eventos de passado imediato, o que, por sua vez, justifica o uso, na variedade peninsular septentrional do espanhol, de expressóes como ¡Se acabó! e ¡Te pillé!. Tal afirmação pode ser justificada com base nos próprios marcadores temporais de antepresente empregados pelo falante (ahora, hoy por la mañana, etc.) e pelo uso da forma pretérita composta (he tenido, ha estado, etc.). Dessa forma, pode haver uma alternância de uso entre as formas composta e simples em razão da complementariedade dos dêiticos que situem o evento passado ainda em relaçáo ao momento de fala (o momento da entrevista).

Tomando o fato de que duas regióes analisadas, especificamente, Galicia e Valencia, apresentem idiomas cooficiais ao espanhol, respectivamente, o galego e o catalão, e que isso não tenha sido considerado como categoria de análise, em questão, a cooficialidade do espanhol com outras línguas; foi possível, nesta pesquisa, averiguar que: (i) na região da Galicia, houve uma alternância de marcadores temporais de antepresente e anterioridade no que diz respeito ao uso do perfecto simple; enquanto (ii) na regiáo da Valencia, não houve uma alternância no uso dos marcadores temporais, sendo empregado, para o perfecto compuesto, marcadores temporais de antepresente; e, para o perfecto simple, marcadores temporais de anterioridade. Isso pode ser constatado nos casos de (22) a (25):

(22) bueno ahora ya cambió porque antes teníamos un aula con <alargamiento/> máquinas de escribir / (SANTIAGO DE COMPOSTELA - ENTREVISTA 04)

(23) eeh/hace trece años // eeh / que lo que hice fue pedir un permiso sin sueldo y <alargamiento/> // con la mochila al hombro pues me fui a <alargamiento/> / a Chile y me lo recorrí // (SANTIAGO DE COMPOSTELA - ENTREVISTA 05)

(24) bueno / tú nos has dicho abora Juan que<alargamiento/> <vacilación/> empiezas a trabajar a las dos de la madrugada / asi que puedes ir de cena (VALENCIA - ENTREVISTA 01)

(25) yo cuando fui en el año noventa y dos tenían una <vacilación/> televisión de trenta y dos 
pulgadas que aqui no en mi casa no la teníamos (VALENCIA - ENTREVISTA 04)

Acredita-se, em relação à região da Galicia, que isso se deva ao fato de o galego, assim como o português, não apresentar um correspondente direto para o perfecto compuesto do espanhol, sendo empregado, portanto, pelo falante, marcadores temporais de antepresente e anterioridade juntamente com o perfecto simple. De acordo com Soto García (2012), a língua galega apresenta apenas o pretérito perfeito (ou pretérito indefinido) para expressar a anterioridade dos fatos. Desse modo, parece "natural", conforme Gómez Seibane (2012), que os falantes nativos de galego não façam o uso adequado dos pretéritos perfecto simple e perfecto compuesto em espanhol, como no exemplo: Tu hermano Fernando cantó este año la nobena a Nuestra Señora por tu intención (GÓMEZ SEIBANE, 2012, p. 95); podendo alternar também com o verbo tener do espanhol como verbo auxiliar nos tempos compostos por influência da língua galega, como nos exemplos: Las novedades del regimiento te las tengo escritas muchas veses / Bastantes delixensias tenemos echas para su libertad / Aunque antes de aora te tengo escrito / El fransés tiene echo los tratados de la paz con Inglaterra (GÓMEZ SEIBANE, 2012, p. 95-96).

Especificamente, em relação a Galicia, pode-se atestar o uso de marcadores temporais típicos de uso do perfecto compuesto, sendo empregados para ancorar o perfecto simple, como se pode averiguar de (26) a (29):

(26) este año por ejemplo marchamos el jueves por la noche y volvemos el lunes / (SANTIAGO DE COMPOSTELA - ENTREVISTA 01)

(27) y lo hago desde hace muchos años // y no hago otras historias o sea nunca me metí asi en historias gordas / no / porque $m$ <palabra_cortadal> / (SANTIAGO DE COMPOSTELA ENTREVISTA 03)

(28) yo siempre que trabajé siempre o sea siempre hizo eso / y no no me / perjudicó nunca en absoluto / <énfasis> para nada <lénfasis> o sea para nada yo / trabajaba de visitador médico / (SANTIAGO DE COMPOSTELA - ENTREVISTA 03)

(29) bueno abora ya cambió porque antes teniamos un aula con <alargamiento/> máquinas de escribir / (SANTIAGO DE COMPOSTELA - ENTREVISTA 04)

De (26) a (29), é possível ver que marcadores temporais típicos de antepresente (este año, nunca, siempre e ahora) são empregados pelos falantes de galego para ancorar o pretérito perfecto simple.

No tocante à região da Valencia, pondera-se que o fato de o cataláo apresentar um correspondente direto para o perfecto compuesto do espanhol e outro correspondente para o perfecto simple induz o falante a fazer a distinção no uso dos marcadores temporais de antepresente para aquele e de anterioridade para este. De acordo com Kempas e Samaniego (2007), a língua catalana apresenta as formas pretéritas de perfecto simple e perfecto compuesto similares ao espanhol, possuindo, levemente, algumas variaçóes em alguns contextos de uso. Dessa forma, os falantes nativos de catalão conseguem diferenciar, de maneira análoga, os usos entre as formas pretéritas simples e composta do espanhol, como nos exemplos: (i) no pretérito perfecto compuesto - No he sentit el que has demanat (cataláo) / No he oído lo que has preguntado

\begin{tabular}{c|c|c|c}
\hline Revista Linguagem em Foco & Fortaleza, CE & v. 12 n. 1 & ISSN 2674-8266 \\
\hline
\end{tabular}


(espanhol) (KEMPAS; SAMANIEGO, 2007, p. 27); e (ii) no pretérito perfecto simple-Anaren al mercat ahir al matí (catalão) / Fueron al mercado ayer por la mañana (espanhol) (KEMPAS; SAMANIEGO, 2007, p. 29).

Em resumo, a língua materna, o galego e o cataláo, pode interferir na performance do falante (as pessoas entrevistadas procedentes da região, respectivamente, da Galicia e da Valencia) ao falar o espanhol (língua oficial da Espanha).

\section{CONSIDERAÇÓES FINAIS}

Ao longo deste trabalho, foi dissertado acerca do uso dos pretéritos perfecto simple e perfecto compuesto na variedade septentrional do espanhol peninsular. Para isso, foram selecionadas entrevistas das cidades de Alcalá de Henares, Madrid, Santiago de Compostela e Valencia, em que foram selecionadas as formas pretéritas simples e composta que eram ancoradas por marcadores temporais de antepresente (hoy, esta semana, este mes, ahora, etc.) e de anterioridade (ayer, la semana pasada, el outro año, etc.).

Foram encontradas 316 ocorrências de ambas as formas, sendo 55,1\% de pretérito perfecto compuesto e $44,9 \%$ de perfecto simple. Isso se deu, em razão de a forma composta apresentar mais matizes de uso do que a forma simples, haja vista que pode ser empregada para ser utilizada em diferentes tipos de interpretações, tais como de: antepresente, perfectiva ou aoristo, pressuposição existencial, prospectiva ou planificação, habitual ou interativa, experiencial, aspecto contínuo e fatos recentes ou passado imediato. Foi constatado também que, no geral, a forma composta é empregada por meio de marcadores temporais de antepresente, enquanto a forma simples é ancorada por meio de marcadores de anterioridade.

No entanto, foi averiguado casos em que marcadores temporais de anterioridade ancoraram o perfecto compuesto, e marcadores de antepresente aportaram o perfecto simple. Isso se justificou, em virtude de a forma composta assinalar uma percepção subjetiva do evento como algo recente e relacionado ao momento de fala, ampliando, portanto, a semântica temporal dos marcadores de anterioridade empregados pelo falante. No que diz respeito à forma simples, verificou-se que ela foi ancorada por meio de marcadores de antepresente, o que é justificável, se se considera que o perfecto simple tem relaçáo com um antigo vestígio de uso desta forma com eventos de passado imediato, como em alguns expressóes típicas da variedade septentrional peninsular, tais como: ¡Se acabó! e ¡Te pillé!.

Foi averiguado ainda que os usos de ambos os pretéritos pode sofrer influência da língua materna do falante, especificamente das regiôes em que há uma língua cooficial: (i) na Galicia, o galego, que por não apresentar um correspondente direto para a forma composta do espanhol, fez com que alguns falantes usassem os marcadores temporais de anterioridade e de antepresente para ancorar o pretérito perfecto simple; por sua vez, na (ii) em Valencia, o catalão, por apresentar correspondentes diretos para as formas simples e composta do espanhol, possibilitou que os falantes empregassem os marcadores temporais de antepresente para o perfecto compuesto e os marcadores de anterioridade para o perfecto simple.

Por fim, pondera-se que os usos dos pretérito perfecto simple e perfecto compuesto podem ainda apresentar diferentes tipos de interpretação, a depender do contexto de uso, podendo, na medida do possível, coocorrerem em algumas situaçôes de uso. Isso pode acarretar em uma sobreposição de uma 
forma sobre a outra, sendo, portanto, necessário a realização de alguns estudos que consigam explicitar o uso dos marcadores de antepresente e de anterioridade na ancoragem das formas pretéritas simples e composta do espanhol na variedade septentrional peninsular.

\section{REFERÊNCIAS}

GÓMEZ SEIBANE, S. Algunos fenómenos sintácticos del español en Galicia (1767-1806). Anuario de Estudios Filológicos, v. 35, 2012, p. 85-102. Disponível em: https://bit.ly/2uUJTwM. Acesso em: 17 jan. 2020.

KEMPAS, I. Estudio sobre el uso del pretérito perfecto prehodiernal en el español peninsular y en comparación con la variedad del español argentino hablada en Santiago del Estero. 2006. 337f. Tese (Doutorado em Letras) - Programa de Pós-Graduação em Letras, Universidade de Helsinki, Finlândia. Disponível em: https://bit.ly/38x4NAv. Acesso em: 17 jan. 2020.

KEMPAS, I; SAMANIEGO, A. L. En torno a la elección de los tiempos pasados aorísticos en catalán/ valenciano por hablantes bilingües. Revista Sintagma, v. 19, 2007, p. 23-38. Disponível em: https://bit. ly/37f9RcV. Acesso em: 17 jan. 2020.

LOCHTE, M. C. El Pretérito Perfecto Compuesto y su contraste con el Pretérito Perfecto Simple en las variedades del español. 2014. 105f. Dissertação (Mestrado em Linguística) - Programa de PósGraduação em Ensino de Espanhol e Catalão como Segunda Língua, Universidade de Girona, Espanha. Disponível em: https://bit.ly/36h4Grw. Acesso em: 17 jan. 2020.

OLIVEIRA, L. C. de. As duas formas do pretérito perfeito em espanhol: análise de corpus. 2007. 130f. Dissertação (Mestrado em Linguística) - Programa de Pós-Graduação em Linguística, Universidade Federal de Santa Catarina, Florianópolis. Disponível em: https://bit.ly/30Pb2NK. Acesso em: 17 jan. 2020.

REAL ACADEMIA ESPAÑOLA. Nueva Gramática de la Real Academia Española. Madrid: Editorial Espasa, 2010.6741p.

SANTOS, C. F. dos. Variaçáo e mudança lingüística dos pretéritos simples e composto, uma perspectiva sociolingüística e discursiva: amostras de Madri, Cidade do México e Buenos Aires. 2009. 259f. Dissertação (Mestrado em Letras Neolatinas) - Programa de Pós-Graduação em Letras Neolatinas, Universidade Federal do Rio de Janeiro, Rio de Janeiro. Disponível em: https://bit.ly/2NQyBAu. Acesso em: 17 jan. 2020.

SOTO GARCÍA, Á. Sobre los tiempos compuestos en el gallego actual. 2012. 27f. Monografia (Faculdade de Filologia) - Departamento de Filologia Clássica, Universidade de Pontevedra, Espanha. Disponível em: https://bit.ly/38113Ci. Acesso em: 17 jan. 2020. 